UDC 338.054:330.17/1

P. Garasym, O. Gerasymenko, M. Garasym

\title{
CONCEPTS OF FIRMNESS AND BALANCING IN MARKETING LOGISTICS
}

\begin{abstract}
Concepts of firmness and balancing are considered. Place of firmness and balancing in marketing logistics is defined.

The authors have come to the conclusion that the system which is considered stable for any moment is not necessarily simultaneously balanced. According to the integrated continuum of logistics development intensity and marketing concepts balancing of marketing logistics have a place in social and ethical marketing concept. Firmness of marketing logistics can be observed in any point of continuum if situation is constant for a long time.
\end{abstract}

Key words: marketing logistics, concepts, firmness, balancing, continuum.

Introduction. During economic crisis supporting firmness and balancing in various spheres of economy is of particular significance. This is also true about marketing logistics.

Now marketing, whose centre of attention is the interests of buyers, is in the process of revival. It is displayed in the evolution of marketing concepts, in particular, in occurrence of numerous directions of using marketing concepts. In this article the authors deal with firmness and balancing in the sphere of marketing logistics.

Questions concerning development of marketing logistics were considered by A. Izekenova, F. Kotler, G. Plahuta, I. Popova, R. Taylor and others. But firmness and balancing in general and of marketing logistics, in particular, still remains insufficiently investigated and definitely demands additional attention. The purpose of the authors is research of concepts of firmness and balancing in marketing logistics. The tasks set are: to consider concepts of firmness and balancing; to define the place of firmness and balancing in marketing logistics.

Concepts of firmness and balancing. As a whole, the concept of firmness is fundamental; it is impossible to realise economic growth and public progressive development without it. This concept began to be used widely in the humanitarian sphere scientific literature only in the end of XX century. In the meantime in technical sphere it became widely used in the end of XIX century after the concept of firmness has been defined and theorems about firmness and instability of technical systems were formulated.

Now the term "firmness" is widely used in such concepts as financial system firmness, industry structure firmness, proof growth company, physical firmness of goods production etc. But, unfortunately, only in a few works there are accurately formulated necessary conditions of firmness, and also necessary and sufficient conditions of developing instability of the whole society and its separate elements.

It is necessary to notice that though at first sight concepts of firmness and balance of a separately taken system are equivalent, actually between them there is an exact difference.

Thus, the system that is considered at certain moment as stable is not necessarily is simultaneously balanced. And the process of any system balancing obviously contradicts to main principles of firmness.

In general, concepts of firmness and balancing can be displayed with the help of corresponding schemes (fig. 1 and 2). In particular, in fig. 1 it is seen that firmness is characterised by the system ability to return to the initial condition of comparison of positive and negative influence factors over time.

In addition, it is necessary to notice that in this case the simplified variant is considered in which the system is firm and balanced (because of the conformity of positive and negative influence factors, the aforementioned influences being equal to zero). The same situation would be observed in the condition of placing the system firmness point on one of the medians of any quarter of positive and negative factors. And in case of any other placing of a firmness point, the system would be considered as firm in the presence of positive or negative misbalancing.

The action of an element of balancing is schematically presented in fig. 2. Unlike the previous scheme, there is a change of the system condition over time. The main purpose in this case is searching for the ways to balance positive and negative factors influencing the investigated system. 


\section{P. Garasym, O. Gerasymenko, M. Garasym}

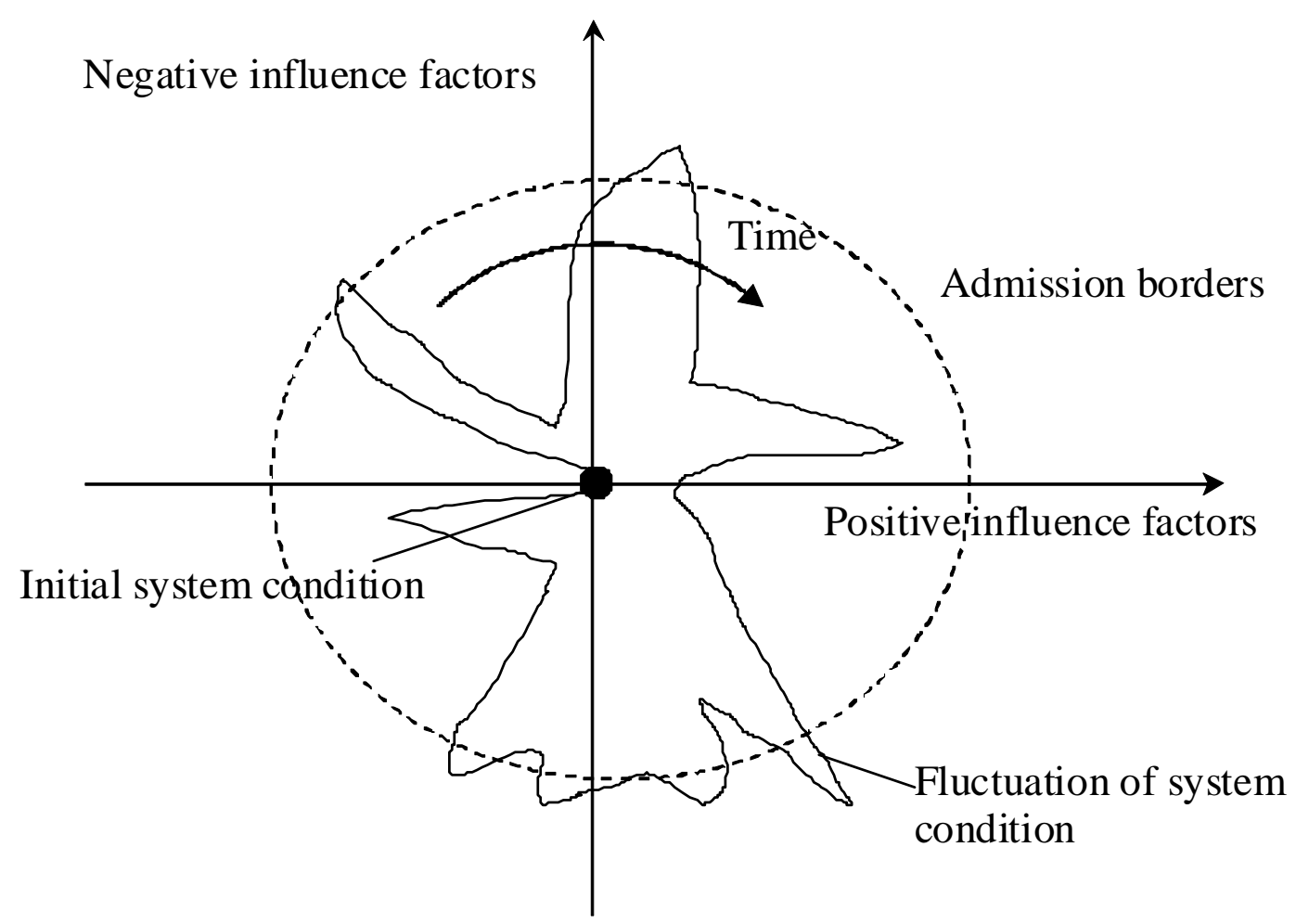

Fig. 1. The schematic display of the separately taken system firmness element action principle Source: [1]

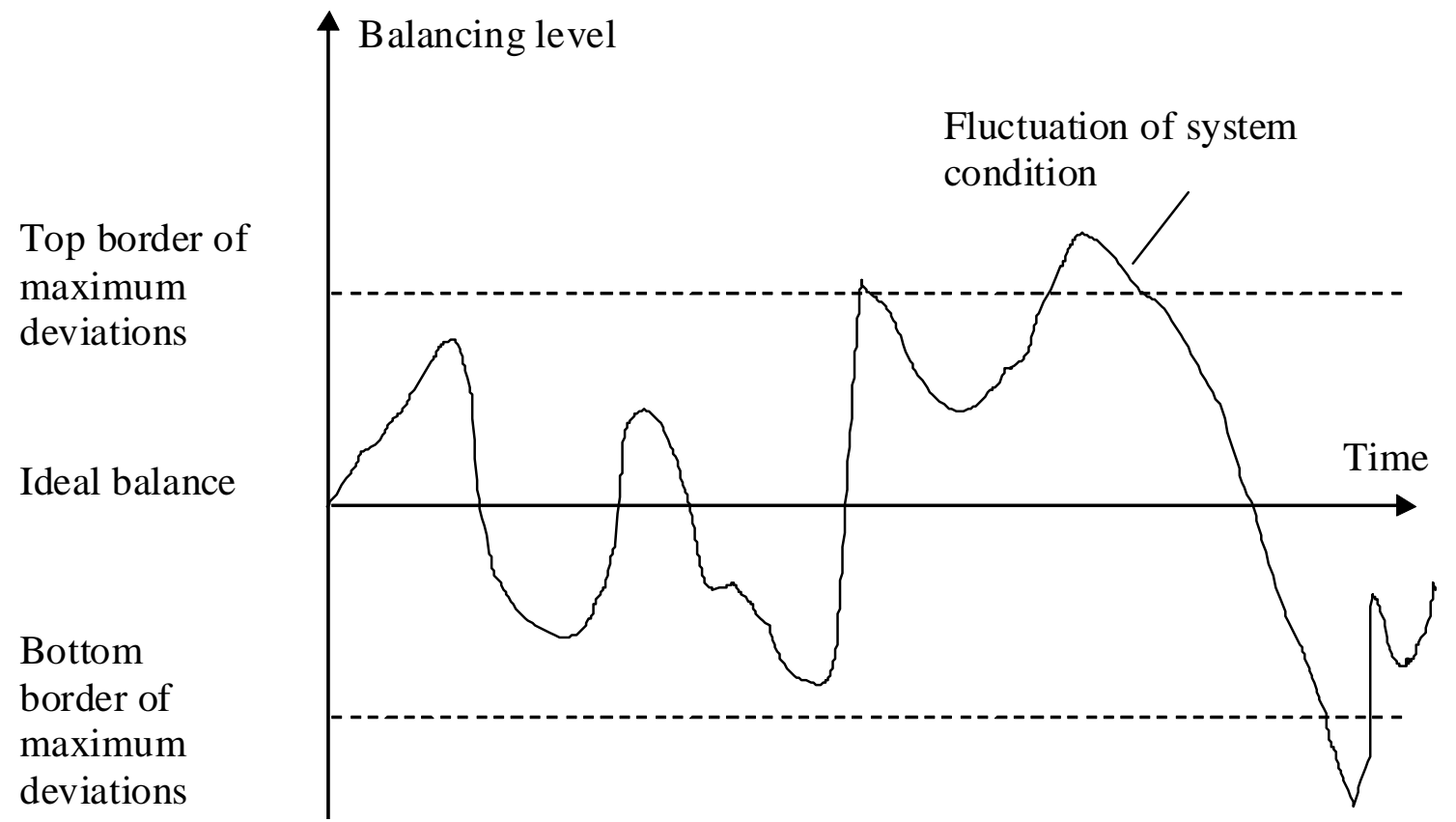

Fig. 2. The schematic display of separately taken system balance element action principle Source: [1]

It is also necessary to remember that close to concept "balance" there is its direct antipode, or "unbalance" that confirms necessity of adequate measures for system reduction in a balance condition more visually.
Unbalance as something imperfect exists from the origin of society. Even at constant tracing of negative tendencies in ideally balanced environment, any (at first sight insignificant) influence factor can essentially infringe a condition of balance and will 


\section{Concepts of firmness and balancing in marketing logistics}

lead to unbalance. Certainly, it is possible to express the opinion that balancing of environment (including global financial system) is superfluous, unnecessary in the long run influence of positive and negative factors will be counterbalanced, and time unbalance from which we cannot completely be protected, will avoid nobody, and in addition will stimulate development of concrete territory. But it is far not so. Self-balancing is possible only at minimum (or zero) state influence on the financial processes, and it basically is impossible because of existence of external influence and necessity of fulfilment state functions (at least because of the requirement of the existence justification). To some extent, selfbalancing occurs in the long-term period, but time necessary for a complete equilibration of system without additional actions is extremely difficult to measure, it is almost impossible. And, consequently, such expectation of "the best times" may be considered groundless [1].

It is necessary to note that ideal balance (as well as the absolute unbalance) is practically impossible to reach. Therefore it is necessary to speak not about balance achievement but about a maximum level of balance (or minimum unbalance).

Firmness and balancing in marketing logistics. We should not underestimate the role of marketing at enterprise in revealing steady buyers' preferences and maintaining steady market positions. But in practice marketing programs are not always supported by necessary financial maintenance and coordinated with plans of other functional divisions that can promote occurrence of internal conflicts [2].

According to F. Kotler, marketing has arisen with the advent of the market which causes commodity - money relations between the seller and the consumer of goods, being beneficial for both sides [3]. During sustainable development there is an evolution of marketing or process of constant changes of theory and practice of marketing under the influence of market condition factors, change of consumer behavior and alternativeness of competitors actions, directed on receiving the desirable profit by businesses. It is possible to display marketing evolution by means of dynamics of its concepts. In its turn, marketing concepts are a system and a mainstream of business activity under the influence of market requirements which are expedient in a concrete situation and allow providing profitability. Almost in all F. Kotler's works [3, 4] the basic concepts of marketing are presented. The authors have decided to arrange these concepts on a continuum (fig. 3).

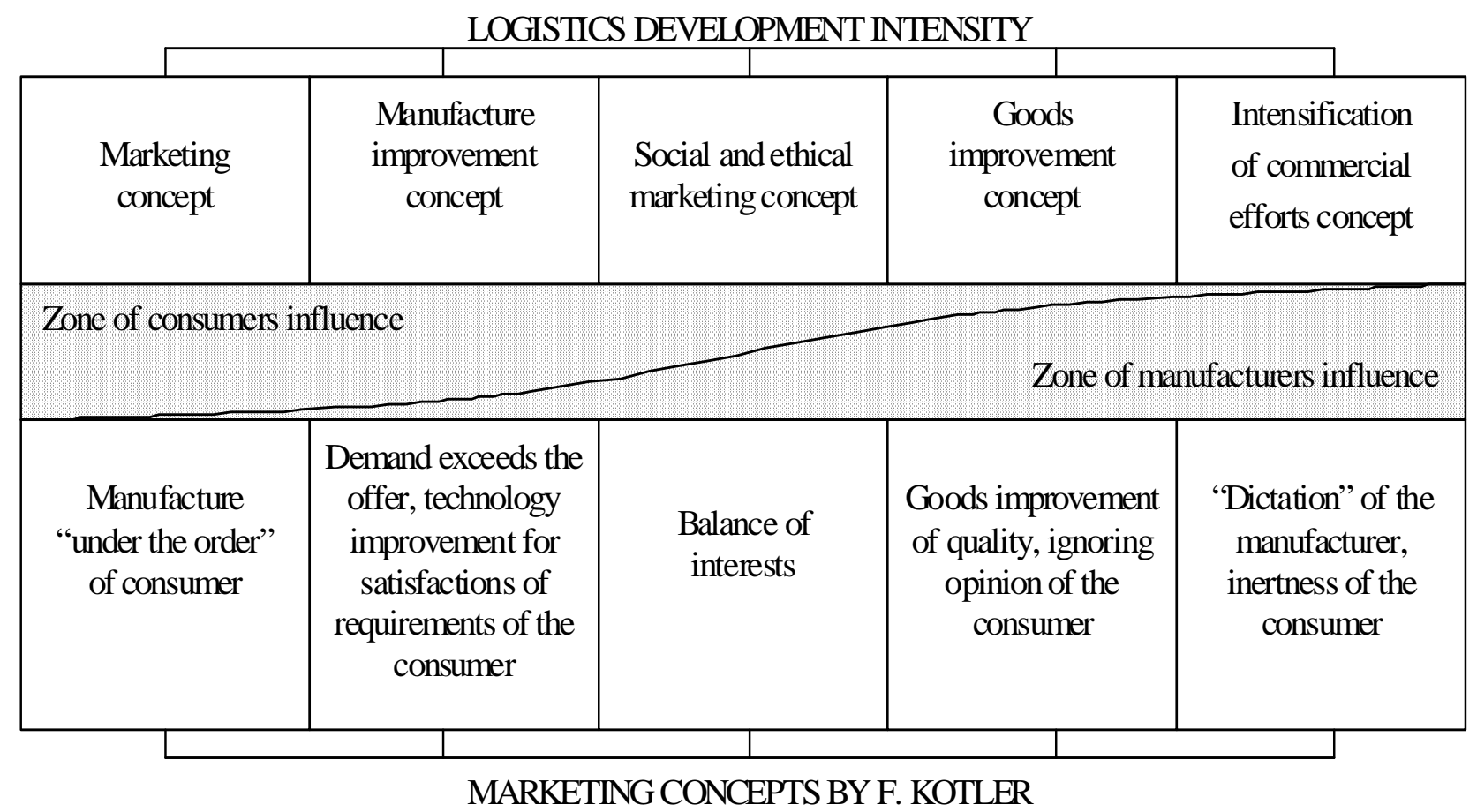

Fig. 3. The integrated continuum of logistics development intensity and marketing concepts Source: Authors' generalisations 


\section{P. Garasym, O. Gerasymenko, M. Garasym}

Intensity of development and value of logistics increases in the process of increasing the consumer influence at a commodity and services market as optimization of resource maintenance, transport decisions, and service improvement are additional factors of influence on consumers' preferences.

As there exists a partial or full "dictation" of the manufacturer in conditions of the minimum influence of the consumer on a commodity and services market, to invest additional funds into developing logistics isn't the manufacturers' urgent requirement. Thus, value of logistics in the struggle for the consumer, in this case, remains practically imperceptible.

Principal aims of introducing and using marketing in Ukraine in the period of its transition to market economy have been summarized by V. Hrutsky:

1. Assistance in transforming work into productive activities.

2. Economy of time and other non-material and material resources in carrying out activities characteristic to market economy.

3. Application of advanced foreign administrative technologies in the country during its transition to market economy.

4. Transformation of bureaucratic economy into free business.

5. Effective participation in the international market economy.

6 . The correct use of foreign investments into economies of the Post-Soviet state [5].

Later the science of marketing developed in the following way: in the early 90s of XX century the majority of educational literature on the marketing theory contained up to $95 \%$ of the material from F. Kotler's books; there were attempts to apply features of domestic marketing in the operation of Ukrainian enterprises later. In references the differential approach to marketing activities is reflected, the description of the theory and practice of specialized marketing (integration of the classical theory of marketing and features of concrete entity of marketing activities) is given as the result.

Development of scientific activity in the sphere of marketing in Ukraine began in the midnineties of XX century. Thus, specialization and differentiation of marketing actions became a feature of marketing science. Later in 1997 the Ukrainian Association of Marketing was created. Its members were responsible for almost $90 \%$ of marketing research in Ukraine.
Key scientists-researchers in the sphere of marketing are in the management of the Association. And among its members one can find research laboratories, advertising agencies etc. The main tasks of the Association are: creation of professional association of experts in marketing; development of standards of their work; development of marketing as a science; formation of the civilized business environment in Ukraine; support of small and average business due to introduction of marketing principles into economic activities; contribution to formation of the transparent mechanism of interaction between scientific institutions, businesses and state bodies in the sphere of marketing education.

The scientific research devoted to problems of sales, satisfaction of consumers requirements, integration of marketing with other economic categories have started to appear in the beginning of second half of XX century.

Thus, P. Druker, D. Kalinton and P. Konvers emphasized the importance of integrated approach, distribution and marketing development in the early sixties. The first printing editions, in which the term "marketing logistics" was used, appeared in the end $60 \mathrm{~s}-$ the beginning of 70s. During the following years management of deliveries developed, can ban, "just in time" being examples of various approaches, which have visually shown necessity of integration of logistic processes with all directions of company activities for the purpose of maximization of their efficiency.

And in the early 90s ideas of the complex, systems approach to management of delivery chains have widely extended. Together with it, the concept of marketing logistics as an approach to management of deliveries chain with market orientation for achievement of competitive advantages was extended. The given concept is based, first of all, on M. Christopher's works which have laid out bases of enterprises functioning taking into account theoretical bases of marketing logistics.

Among other things, it is necessary to notice that the unequivocal approach to definition of the concept of marketing logistics does not exist. Definitions of this concept in works of foreign and Ukrainian researchers differ by degree of detailed elaboration and generalization of the deliveries chain components.

G. Plahuta and I. Popova define marketing logistics (or marketing-logistics) as the activity 


\section{Concepts of firmness and balancing in marketing logistics}

concerning planning, realization and control of physical movement of all kinds of streams (finished goods, materials, information) which are accompanied by goods movement through the selected channel from the manufacturer to the consumer for the purpose of satisfying consumers requirements and getting profit [6].

Authors focus attention on the part of deliveries chain which works with consumers as on the base component of marketing logistics. It is also necessary to take into account certain aspects of personnel logistics, some of which have already been objects of the authors' research [7].

F. Kotler in his work "Marketingmanagement" also pays considerable attention to the concept of marketing logistics. He defines it as the approach according to which the manufacturer should analyze market requirements, and only after that form a chain of deliveries. According to Kotler, the marketing logistics includes planning, introduction and control of material streams, from points of an origin to final destinations for the purpose of buyers' requirements satisfaction [3].

Martin Christopher, one of the founders of the "marketing logistics" concept in his works does not provide a uniform exact concept, but notices that the marketing logistics concentrates on how servicing can be used for gaining competitive advantages. Besides, it is directed towards management of interaction between marketing and logistics for the purpose of coordinating perspective strategies in a context of wider chain of deliveries [8].

Marketing logistics is defined as planning, organization, calculation and control, analysis regulation of all operations on transporting and warehousing, related to the flow of finished goods from the manufacturing line to the products arrival to the market; distributional channels, necessary for organization, and interaction of support between the manufacturer and the market are also included.

Summary. Though at first sight concepts of firmness and balance of a separately taken system are equivalent, actually there is an exact difference between them. The system which is considered stable at a given moment is not necessarily simultaneously balanced. The process of any system balancing obviously contradicts to the main principles of firmness. The ideal balance (as well as the absolute unbalance) is practically impossible to reach. Therefore it is necessary to speak not about balance achievement but about a maximum level of balance (or minimum unbalance).

According to the integrated continuum of logistics development intensity and marketing concepts, balancing of marketing logistics has a place in social and ethical marketing concept. Firmness of marketing logistics can be observed in any point of continuum if situation is constant for a long time.

In their further research the authors plan to determine the influence of marketing logistics firmness and balancing on the efficiency of Ukrainian enterprises.

\section{References}

1. Gerasymenko O. Influence of Economic Firmness on the Efficiency of the Mechanism of the Balanced Functioning of the Global Financial System / O. Gerasymenko // "Jaunuju mokslininku darbai”, Šiauliu universitetas, 2012, \# 2 (35).

2. Chuhraj N. Profit marketing: an interconsistency of marketing and financial decisions: monography / N. Chuhraj, I. Mavrina. - Lviv: Publishing house of the Lviv polytechnics, 2012.

3. Kotler F. Marketing management / F. Kotler. SPb.: Piter, 2005.

4. Kotler F. Marketing bases / F. Kotler, P. Armstrong. M., Williams, 2003.

5. Dligach A. Tendencies of marketing development in Ukraine / A. Dligach // "Marketing in Ukraine", 2005, \# 1.

6. Plahuta G. Marketing and logistics integration into management system / G. Plahuta, I. Popova // Marketing: the theory and practice", Scientific works of the East Ukrainian national university of a name of Vladimir Dal, 2008, Vol. 14.

7. Garasym P. Features of taking into account of individual socionic type in personnel logistics process / P. Garasym, O. Gerasymenko, M. Garasym // “Zarzadzanie i marketing”, Monography, Krakow, AT Wydawnictwo \& Authors, 2014.

8. Christopher M. Marketing Logistics / M. Christopher, H. Peck. - Oxford, Elsevier ButterworthHeinemann, 2003. 
